Jul 1st, 12:00 AM

\title{
Modelling the Asymmetric Volatility of Electronics Patents in the USA
}

Felix Chan

Dora Marinova

Michael McAleer

Follow this and additional works at: https://scholarsarchive.byu.edu/iemssconference

Chan, Felix; Marinova, Dora; and McAleer, Michael, "Modelling the Asymmetric Volatility of Electronics Patents in the USA" (2002). International Congress on Environmental Modelling and Software. 79. https://scholarsarchive.byu.edu/iemssconference/2002/all/79

This Event is brought to you for free and open access by the Civil and Environmental Engineering at BYU ScholarsArchive. It has been accepted for inclusion in International Congress on Environmental Modelling and Software by an authorized administrator of BYU ScholarsArchive. For more information, please contact scholarsarchive@byu.edu, ellen_amatangelo@byu.edu. 


\title{
Modelling the Asymmetric Volatility of Electronics Patents in the USA
}

\author{
Felix Chan $^{a}$, Dora Marinova ${ }^{b}$ and Michael McAleer ${ }^{a}$

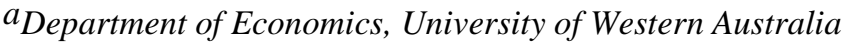 \\ $b_{\text {Institute for Sustainability and Technology Policy, Murdoch University }}$
}

\begin{abstract}
This paper analyses the asymmetric volatility in Japanese electronics and electrical equipment (hereafter, electronics) patents in the USA from 1975 to 1997. The number of patents has been increasing steadily over time and the electronics industry has a 30\% share of total Japanese patents in the USA. Thus, such patents reflect a strategic development by Japanese companies for the US market. The time-varying nature of the volatility of the ratio of the number of electronics patents registered in the USA from Japan to the total number of electronics patents registered in the USA is examined for a variety of asymmetric models using data for the period January 1975 to December 1997. $\mathrm{AR}(1)$-EGARCH$(1,1)$ is found to be the most suitable model, but both the AR(1)-GARCH(1,1) and AR(1)-GJR(1,1) models provide interesting results for the electronics industry.
\end{abstract}

\section{INTRODUCTION}

Once slandered as a nation of copycats, Japan is now widely recognised as an innovator [Flath, 2000]. Government science and technology policies have actively encouraged research and development (R\&D) spending, particularly from companies. In 1997, R\&D expenditure represented $2.9 \%$ of the country's GDP, the largest share in the world, with contributions from the private sector being as high as 73\% [DISR, 2000].

Heavy investment in $R \& D$, coupled with strategies for quick economic returns, has resulted in the immediate commercial application of most Japanese technological inventions. It also translated into activities such as foreign patenting in order to protect the intellectual property rights of companies. For the period 1976 to 1999, Japan had the largest total number of American patents held by foreign residents and companies, and also ranked fourth according to patent intensity (that is, the number of patents per capita), behind only Switzerland and two very small-sized economies (Liechtenstein and Monaco) [Marinova, 2001].

The broadly defined "high technology" industry of electronics and electrical equipment (hereafter, electronics) accounted for $25 \%$ of the R\&D spending in Japan in fiscal year 1995 [Flath, 2000]. This industry has been intensively developed by other industrial countries, such as the USA, Germany and the Scandinavian countries. Nevertheless, the Japanese presence in international markets, and in the US market in particular, has been and continues to be highly prominent. During the 1970s and 1980s, Japan broke long-standing American monopolies in this industry. In order to protect and extract benefits in the USA from their innovations, Japanese companies have consistently registered the highest number of foreign patents. In 1997, the share of granted applications lodged by Japanese individuals and companies at the US Patent and Trademark Office (PTO) in all granted patent applications was $17 \%$ for the electronics industry. The importance of this industry sector is confirmed by the fact that in 1997 electronics accounted for more than $45 \%$ of the total number of US patents granted to Japanese residents. One explanation for such high patenting activity is that Japanese companies perceive exclusive intellectual property rights, not as a reward for fundamental discoveries and inventiveness, but as a "coordinating mechanism for innovation within the market system" [Foray, 1995, p.109].

The paper examines the trends and asymmetric volatility in Japanese patenting in the USA for the electronics industry. The plan of the paper is as follows. Section 2 describes the data. The statistical trends in the patent data are examined in Section 3. Section 4 briefly discusses the time-varying GARCH, GJR and EGARCH models. Empirical results are presented in Section 5, where policy implications are also analysed. Some concluding remarks are given in Section 6.

\section{DATA DESCRIPTION}

The empirical study is based on patent data from the US PTO, available on-line and accessible through the site's search engine (http://164.195.100.11/netahtml/searchadv.htm). The time series data consist of monthly observations for the number of patents with application dates between 1975 and 1997. The monthly data for Japanese patents in the electronics industry for 19751997 were extracted from the US PTO database in March 2001. Subsequently, there was a change in the settings of the search engine on the web site which prevented the same search algorithm from being used to update the information for patents lodged in 1998. The new settings only allow a smaller number of search categories. As the use of the new settings would lead to a higher double-counting of patents belonging to more than one electronics and electrical equipment class, the data extracted in March 2001 are used in this paper. 
The date of lodgment of granted applications for the time series is used instead of the date of issue of patents to avoid organisational delays associated with the complicated process of receiving a patent (which includes procedures such as examination, expert review, and appeals). Consequently, the data on patents by date of application represent more accurately the process of commercial protection for intellectual property and innovative outcomes from R\&D.

Although data on US patents are available from 1790, significant patenting activities occurred only after 1975 , followed by an unprecedented surge in the 1980s and 1990s [Kortum and Lerner, 1999; Arundel and Kabla, 1998]. The US PTO updates the information on patents granted on a fortnightly basis. However, the time from application to the granting of a patent can be very long ${ }^{1}$, and is estimated to be two years on average [Marinova, 2001]. Thus, any data on granted patents with application dates in 1999 and 2000 will be incomplete. Data for 1998 and some previous years will also be subject to additions from patents whose approval has taken longer than average. For this reason, data from 1975 to 1997 are used in this paper.

The classification systems used by the PTO, namely the Current US Classification and the International Patent Classification, do not provide a direct link between patent class and industry application. This issue has been discussed by, among others, Mansfield [1986], Pavitt [1988], Griliches [1990], and Grupp [1994]. In order to deal with this problem, patent classes need to be allocated to certain industries [Amendola et al., 1998]. In this paper, the Current US Classification is used $^{2}$. The electronics and electrical equipment sector is broadly covered by 68 different patent classes.

\section{TRENDS IN PATENT DATA}

Figure 1 shows the monthly data for US patents in the electronics industry issued to Japanese residents and total electronics patents, with application dates between January 1975 and December 1997. Both variables display upward trends. Total patents in the electronics industry have increased rapidly over time, especially in the latter part of the sample. It is interesting to note that Japan had a relatively late start in the 1970s, but quickly caught up in the early 1980s. The contributions by Japan in this industry are highly prominent, with the share of US patents held by Japanese residents being

\footnotetext{
${ }^{1}$ In the USA, patents are granted relatively quickly, particularly in comparison with the Japanese patent system where the time from application to grant can be as long as ten years [Flath, 2000].

${ }^{2}$ The patent classes of the Current US Classification system (or CCL), associated with electronics and electrical equipment are as follows $109,174,200,218,219,236,257,307,310,313,314,315,318,320$, $322,323,324,326,327,329,330,331,332,333,344,335,336,337$, $338,341,345,346,349,360,361,362,364,365,368,369,371,372$ $373,374,375,377,378,381,382,385,386,388,392,395,438,439$, 445, 477, 505, 701, 702, 704, 705, 706, 707, 711, 901 and 902. The PTO has established a concordance between the US and the international patent classes, which can be accessed on its web site.
}

consistently around $30 \%$ since 1985 . Moreover, the two series are highly correlated, with a correlation coefficient of 0.941 .

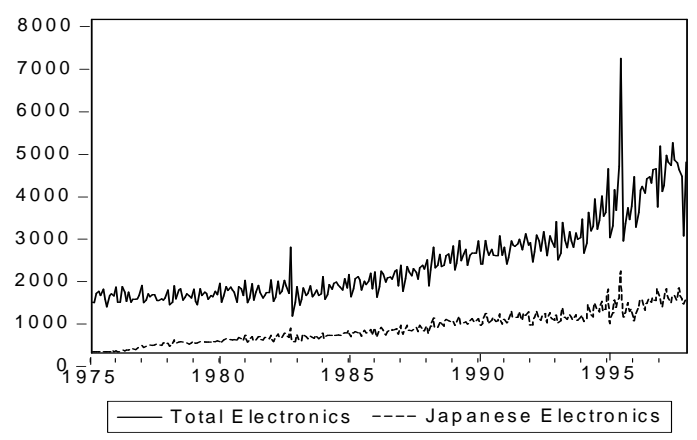

Figure 1: US Patents by Japanese Residents in the Electronics Industry and Total Electronics Patents by Date of Application, January 1975 - December 1997

Previous studies, such as the European innovation survey [Arundel and Kabla 1998, p. 129], Mansfield [1986] and Pavitt [1997], argue that patents are of greatest value in sectors where the cost of copying an innovation is considerably less than the initial cost of inventions. Examples of such sectors are chemicals, petroleum and pharmaceuticals. The electronics industry does not fall into this category, and patent protection is expected to be much less important. The cost of imitation in electronics and electrical devices may well be comparable to the cost of the initial inventions. It is interesting to note that, although companies in this sector do not consider patenting to be crucial for the commercialisation of their inventions, they still apply for patents. Mansfield [1986] has argued that the benefits of patent protection, such as delays in imitation and bargaining power, exceed the costs involved, and has estimated that over $60 \%$ of all patentable inventions in this industry are actually patented.

This sectoral analysis does not provide an indication as to whether the electronics industry represents a technological strength for Japan. As already observed, not all industries have the same patenting propensities. Do Japanese companies generally patent across all sectors, or does Japan have a specific emphasis and potential in a particular industry? The technological specialisation index (TSI) (alternatively, 'revealed technology advantage', as described by Patel and Pavitt [1995], or the economic concept of 'comparative advantage') provides insight into this issue. This index is calculated as follows:

$$
I_{i j}=\frac{P_{i j} / \sum_{i} P_{i j}}{\sum_{j} P_{i j} / \sum_{i} \sum_{j} P_{i j}}
$$

where $I_{i j}$ is the index for sector $i$ in country $j, P_{i j}$ is the number of patents issued to sector $i$ in country $j$, $P_{i j} / \sum_{i} P_{i j} \quad$ is the ratio of patents in sector $i$ for country 
$j$ to all patents in country $j$, and $\sum_{j} P_{i j} / \sum_{i} \sum_{j} P_{i j}$ is the ratio of total patents for sector $i$ in all countries to all patents in all countries. Therefore, $I_{i j}$ reflects the relative strength of sector $i$ in country $j$ to sector $i$ in all countries.

The index corrects the contribution of a particular industry to the national number of patents with the overall patent propensity of the same industry internationally. Thus, an index higher than 1 is indicative of a country's national strength: the higher is the value, the more important is that industry at a national level. The reverse also holds, with lower figures representing lower levels of patenting activities. According to Paci et al. [1997, p. 33], the TSI is preferred to simple percentage quotas of patents in each sector because some industries prefer methods other than patenting for protecting innovations, such as trade secrets, registered trademarks, know-how advantages, and economies of scale.

Figure 2 shows the trends in the TSI for the Japanese electronics industry. Since the late 1970s, electronics has been a well-established technological strength of Japan, with its TSI well above 1 and with an average of just below 1.5. The high share of Japanese patents in electronics is not a specific feature of this industry, but is a strategic technological development on the part of Japanese companies. Numerous studies have confirmed that patenting activities cause subsequent and immediate market changes (see, for example, Soete [1987], Griliches et al. [1991], and Ernst [1995] in the case of German mechanical engineering, and Ernst [1997] for a case-study of CNC-technology in the machine tool industry). This is precisely what has been witnessed with the Japanese presence in international electronics markets, as Japan has been pro-active in securing protection and access to American markets. Overall, it is clear that Japan has been innovative in the electronics industry.

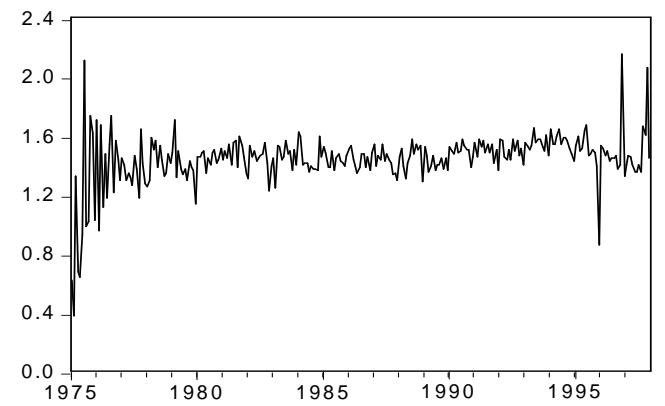

Figure 2: Technological Specialisation Index for the Japanese Electronics Industry, January 1975 - December 1997

\section{GARCH, GJR and EGARCH}

The primary purpose of the following sections is to model the volatility of the ratio of the number of electronics patents registered in the USA from Japan to the total number of electronics patents registered in the USA (henceforth, the "patents ratio"). This new approach is based on Engle's [1982] path-breaking idea of capturing time-varying volatility (or uncertainty) using the autoregressive conditional heteroskedasticity (ARCH) model, and subsequent developments forming the ARCH family of models (see, for example, the surveys of Bollerslev, Chou and Kroner [1992], Bollerslev, Engle and Nelson [1994] and Li, Ling and McAleer [2002]). Of these models, the most popular has been the generalised ARCH $(\mathrm{GARCH})$ model of Bollerslev [1986], especially for the analysis of financial data. In order to accommodate asymmetric behaviour (between negative and positive shocks, or movements in the time series), Glosten, Jagannathan and Runkle [1992] proposed the GJR model. Some further developments have been suggested by Wong and Li [1997], He and Teräsvirta [1999], and Ling and McAleer [2002a, b, c].

Consider the AR(1)-GARCH(1,1) model for the patents ratio, $y_{t}$ :

$$
y_{t}=\phi_{1}+\phi_{2} y_{t-1}+\varepsilon_{t}, \quad\left|\phi_{2}\right|<1
$$

where the shocks (or movements in the patents ratio) are given by:

$$
\begin{aligned}
& \varepsilon_{t}=\eta_{t} \sqrt{h_{t}}, \\
& h_{t}=\omega+\alpha \varepsilon_{t-1}^{2}+\beta h_{t-1},
\end{aligned}
$$

and $\omega>0, \alpha \geq 0, \beta \geq 0$ are sufficient conditions to ensure that the conditional variance $h_{t}>0$. The ARCH (or $\alpha$ ) effect indicates the short run persistence of shocks, while the GARCH (or $\beta$ ) effect indicates the contribution of shocks to long run persistence (namely, $\alpha+\beta)$.

In equations (1) and (2), the parameters are typically estimated by the maximum likelihood method to obtain Quasi-Maximum Likelihood Estimators (QMLE) in the absence of normality of $\eta_{t}$. The conditional loglikelihood function is given as follows:

$$
\sum_{t} l_{t}=-\frac{1}{2} \sum_{t}\left(\log h_{t}+\frac{\varepsilon_{t}^{2}}{h_{t}}\right)
$$

Ling and McAleer [2002c] showed that the QMLE for $\operatorname{GARCH}(\mathrm{p}, \mathrm{q})$ is consistent if the second moment is finite, that is, $E\left(\varepsilon_{t}^{2}\right)<\infty$. Ling and Li [1997] showed that the local QMLE for $\operatorname{GARCH}(p, q)$ is asymptotic normal if the fourth moment is finite, that is, $E\left(\varepsilon_{t}^{4}\right)<\infty$, and the model is stationary and ergodic if $E\left(\varepsilon_{t}^{2}\right)<\infty$. Using results from Ling and Li [1997] and Ling and McAleer [2002a, b] (see also Bollerslev [1986], Nelson [1990] and He and Teräsvirta [1999]), the necessary and sufficient condition for the existence of the second moment of $\varepsilon_{t}$ is $\alpha+\beta<1$ and, under 
normality, the necessary and sufficient condition for the existence of the fourth moment is $(\alpha+\beta)^{2}+2 \alpha^{2}<1$.

The effects of positive shocks (or upward movements in the patents ratio) on the conditional variance, $h_{t}$, are assumed to be the same as the negative shocks (or downward movements in the patents ratio) in the symmetric GARCH model. In order to accommodate asymmetric behaviour, Glosten, Jagannathan and Runkle [1992] proposed the GJR model, which is defined as follows:

$$
h_{t}=\omega+\left(\alpha+\gamma D_{t-1}\right) \varepsilon_{t-1}^{2}+\beta h_{t-1},
$$

where $\omega>0, \alpha+\gamma \geq 0, \beta \geq 0$, are sufficient for $h_{t}>0$, and $D_{t}$ is an indicator variable defined by:

$$
D_{t}= \begin{cases}1, & \varepsilon_{t}<0 \\ 0, & \varepsilon_{t} \geq 0 .\end{cases}
$$

The indicator variable differentiates between positive and negative shocks, so that asymmetric effects in the data are captured by the coefficient $\gamma$, with the expectation that $\gamma>0$. The asymmetric effect, $\gamma$, measures the contribution of shocks to both short run persistence, $\alpha+\frac{\gamma}{2}$, and long run persistence, $\alpha+\beta+\frac{\gamma}{2}$. Although the regularity conditions for the existence of moments for the GJR model are now known, there are as yet no theoretical results regarding the statistical properties of the model. For $\operatorname{GJR}(1,1)$, Ling and McAleer [2002a] showed that the regularity condition for the existence of the second moment under symmetry of $\eta_{t}$ is $\alpha+\beta+\frac{1}{2} \gamma<1$, and the condition for the existence of the fourth moment under normality of $\eta_{t}$ is $\beta^{2}+2 \alpha \beta+3 \alpha^{2}+\beta \gamma+3 \alpha \gamma+\frac{3}{2} \gamma^{2}<1$.

An alternative model to capture asymmetric behaviour in the conditional variance is the Exponential GARCH (EGARCH(1,1)) model of Nelson [1991], namely:

$$
\log h_{t}=\omega+\alpha\left|\eta_{t-1}\right|+\gamma \eta_{t-1}+\beta \log h_{t-1},|\beta|<1
$$

There are some distinct differences between EGARCH and the previous two GARCH models, namely: (i) EGARCH is a model of the logarithm of the conditional variance, which implies that no restrictions on the parameters are required to ensure $h_{t}>0$; (ii) Nelson [1991] showed that $|\beta|<1$ ensures stationarity and ergodicity for $\operatorname{EGARCH}(1,1)$; (iii) Shephard [1996] observed that $|\beta|<1$ is likely to be a sufficient condition for consistency of QMLE for $\operatorname{EGARCH}(1,1)$; (iv) as the conditional (or standardized) shocks appear in equation (4), it is likely that $|\beta|<1$ is a sufficient condition for the existence of moments, and hence also sufficient for asymptotic normality of the QMLE of $\operatorname{EGARCH}(1,1)$.

Furthermore, EGARCH captures asymmetries differently from GJR. The parameters $\alpha$ and $\gamma$ in EGARCH $(1,1)$ represent the magnitude and sign effects of the conditional shocks, respectively, on the conditional variance. However, $\alpha$ and $\alpha+\gamma$ represent the effects of positive and negative shocks on the conditional variance in $\operatorname{GJR}(1,1)$.

As EGARCH is non-nested with regard to both GARCH and GJR, the parameters of the non-nested models are not directly comparable.

\section{EMPIRICAL RESULTS}

The purpose of this section is to model the volatility of the patents ratio, namely the ratio of the number of electronics patents registered in the USA from Japan to the total number of electronics patents registered in the USA. The AR(1)-GARCH(1,1), AR(1)-GJR(1,1) and $\operatorname{AR}(1)-E G A R C H(1,1)$, as defined in equations (1)-(2), (1)-(3) and (1)-(4), respectively, are estimated using a rolling window of size 200 for the patents ratio. These estimates and graphs are available on request. The impact of each observation on the estimates and on the second and fourth moment conditions, where appropriate, can be investigated by examining their respective dynamic paths.

The movements in the $\hat{\alpha}$ (or $\mathrm{ARCH}$ ) estimates for the GARCH model exhibit substantial fluctuations from 1975 to the late 1970's, followed by a visible downward trend from the beginning of the 1980's to the late 1990 's. Fluctuations in the early rolling samples may indicate the presence of outliers, structural breaks or a period of abrupt transition. Although there are extreme observations in the 1990's, namely November 1996 and November 1997, there are no outliers or extreme observations in the early rolling samples. The lack of outliers in these rolling samples indicates that the industry was experiencing a transition period during the late 1970 's to early 1980 's. During this period, the number of electronics patents from Japan was growing rapidly. A downward trend in the $\hat{\alpha}$ estimates suggests a decline in the short run persistence of unconditional shocks. Such downward trends are only slightly visible in the $\hat{\beta}$ (or GARCH) estimates. Movements in the $\hat{\beta}$ estimates in the early rolling samples correspond to movements in the $\hat{\alpha}$ estimates, but remain stable after the dramatic decrease in January 1976. Interestingly, the $\hat{\beta}$ estimates remain below 0 for the rest of the rolling samples, which seems to suggest that long run persistence is extremely low. The mean estimates of $\hat{\alpha}$ and $\hat{\beta}$ are 0.233 and 0.07 , respectively, with the latter being especially low for models of time-varying volatility. 
Although the means of the $\hat{\alpha}$ and $\hat{\beta}$ estimates are low, in general, there are 8 rolling windows which fail to satisfy the second moment condition, and a total of 12 rolling windows which fail to satisfy the fourth moment condition. It is important to note that only rolling samples from the transition period fail to satisfy the moment conditions, and the rolling samples after January 1976 satisfy both the second and fourth moment conditions. The mean second and fourth moment conditions are 0.303 and 0.676 , respectively. Although, it is possible that negative $\hat{\alpha}$ and $\hat{\beta}$ estimates may lead to negative estimates of the conditional variance, in this paper all rolling windows with negative $\hat{\alpha}$ and $\hat{\beta}$ estimates yielded positive estimates of the conditional variance.

The movements in the $\hat{\alpha}$ (or $\mathrm{ARCH}$ ) estimates for the GJR model are quite different to those for the GARCH model. Allowing asymmetric behaviour seems to have removed the downward trend in the $\hat{\alpha}$ estimates. Furthermore, the means of both the $\hat{\alpha}$ and $\hat{\beta}$ (or $\mathrm{GARCH}$ ) estimates increase to 0.299 and 0.182 , respectively. Movements in the $\hat{\beta}$ estimates also fluctuate more dramatically than do their GARCH counterparts. The fact that all of the $\hat{\gamma}$ (or asymmetry) estimates are negative, with a mean of -0.178 , implies that negative shocks reduce the volatility in the number of electronics patents registered in the USA. This is an interesting result, being in marked contrast to the empirical results using financial data in which negative shocks (or downward movements in the market) increase volatility (or risk).

Although the number of rolling samples failing to satisfy the second moment condition for the GJR model remains at 8 , only 9 rolling samples fail to satisfy the fourth moment condition. As before, only the rolling samples from the transition period fail to satisfy the second and fourth moment conditions. The mean second and fourth moment conditions are 0.391 and 0.427 , respectively, both of which are substantially different from their counterparts for the GARCH model.

The mean $\hat{\alpha}$ estimate for the EGARCH model is 0.381 , despite the negative estimates in the early rolling samples, namely the rolling samples being with January 1975 and February 1975. An interesting feature of these estimates is the substantial change occurring for rolling samples 61 to 63 (the rolling samples starting in February 1980 to April 1980), in which the $\hat{\alpha}$ estimate first decreases from 0.33 to -0.032 , then increases dramatically to 0.402 and again to 0.595 .

The movements in the $\hat{\gamma}$ estimates for the EGARCH model provide interesting information regarding the asymmetric behaviour of the data. First, $\hat{\gamma}$ starts at a negative value and changes to positive, remaining positive for all subsequent rolling samples until May
1979. Then $\hat{\gamma}$ decreases dramatically from 0.167 to 0.088 , and remains close to 0 for the remaining rolling samples. This seems to suggest that the presence of asymmetric behaviour is not constant over time, which is not supported by the estimated asymmetry in the GJR model.

It is important to note that all $|\hat{\beta}|<1$ for the EGARCH model for all rolling samples, which ensures stationarity and ergodicity. Furthermore, it also seems to suggest consistency and asymptotic normality for QMLE of the EGARCH model, so that valid inferences can be conducted for EGARCH.

\section{CONCLUSION}

The paper analysed the trends and volatilities in patents issued to Japan in the USA from 1975 to 1997, with an emphasis on the electronics industry. The time-varying nature of the volatility of patents registered in the USA by this industry was examined using monthly data. The asymmetric $\mathrm{AR}(1)-\mathrm{EGARCH}(1,1)$ model was found to be suitable for the electronics industry, although the effects of asymmetry seemed to dissipate in more recent years. Estimates from both $\operatorname{AR}(1)-\operatorname{GARCH}(1,1)$ and $\operatorname{AR}(1)-G J R(1,1)$ models for this industry provided unexpected results, which may arise from model misspecification.

\section{ACKNOWLEDGMENTS}

The first author wishes to acknowledge the financial support of an Australian Postgraduate Award and an Individual Research Grant at the University of Western Australia. The second author is most grateful for the financial support of the Australian Research Council and the Department of Economics at the University of Western Australia. The third author acknowledges the financial support of the Australian Research Council.

\section{REFERENCES}

Amendola, G., P. Guerrieri, and P.C. Padoan, International patterns of technological accumulation and trade, in D. Archibugi, and J. Michie (eds.), Trade, Growth and Technical Change, Cambridge University Press, Cambridge, pp. 141-167, 1998.

Arundel, A., and I. Kabla, What percentage of innovations are patented? Empirical estimates from European firms, Research Policy, 27(2), 127141, 1998.

Bollerslev, T., Generalised autoregressive conditional heteroskedasticity, Journal of Econometrics, 31, 307-327, 1986.

Bollerslev, T., R. Y. Chou and K. F. Kroner, ARCH modelling in finance: a review of the theory and empirical evidence, Journal of Econometrics, 52, 5-59, 1992.

Bollerslev, T., R. F. Engle and D. B. Nelson, ARCH models, in R. F. Engle and D. L. McFadden 
(Editors), Handbook of Econometrics, 4 (NorthHolland, Amsterdam), pp. 2961-3038, 1994.

Department of Industry, Science and Resources (DISR), Science and Technology Budget Statement 200001, Australian Government Publishing Service, Canberra, 2000.

Ernst, H., Patenting strategies in the German mechanical engineering industry and their relationship to company performance, Technovation, 15(4), 225$240,1995$.

Ernst, H., The use of patent data for technological forecasting: The diffusion of CNC-technology in the machine tool industry, Small Business Economics, 9(4), 361-381, 1997.

Flath, D., The Japanese Economy, Oxford University Press, Oxford, 2000.

Foray, D., The economics of intellectual property rights and systems of innovation: The persistence of national practices versus the new global model of innovation, in J. Hagedoorn (ed.), Technical Change and the World Economy: Convergence and Divergence in Technology Strategies, Edward Elgar, Aldershot, pp. 109-133, 1995.

Glosten, L., R. Jagannathan, and D. Runkle, On the relation between the expected value and volatility of nominal excess return on stocks, Journal of Finance, 46, 1779-1801, 1992.

Griliches, Z., Patent statistics as economic indicator: A survey, Journal of Economic Literature, 28(4), 1661-1707, 1990.

Griliches, Z., B.H. Hall, and J.A. Hausman, R\&D, patents and market value revisited: Is there a second (technological opportunity) factor?, Economics of Innovation and New Technology, 1, 183-201, 1991.

Grupp, H. The dynamics of science-based innovation reconsidered: Cognitive models and statistical findings, in O. Granstrand (ed.), Economics of Technology, North-Holland, Amsterdam, pp. 223$251,1994$.

He, C., and T. Teräsvirta, Properties of moments of a family of GARCH processes, Journal of Econometrics, 92, 173-192, 1999.

Kortum, S., and J. Lerner, What is behind the recent surge in patenting?, Research Policy, 28(1), 1-22, 1999.

Ling, S., and W.K. Li, On fractional integrated autoregressive moving average time series models with conditional heteroscedasticity, Journal of the American Statistical Association, 92, 1184-1194, 1997.

Li, W. K., S. Ling and M. McAleer, Recent theoretical results for time series models with GARCH errors, Journal of Economic Surveys, 16, 245-269, 2002.

Ling, S., and M. McAleer, Necessary and sufficient moment conditions for the $\operatorname{GARCH}(\mathrm{r}, \mathrm{s})$ and asymmetric power $\mathrm{GARCH}(\mathrm{r}, \mathrm{s})$ models, Econometric Theory, 18, 722-729, 2002a.

Ling, S., and M. McAleer, Stationarity and the existence of moments of a family of GARCH processes, Journal of Econometrics, 106, 109-117, 2002b.

Ling, S. and M. McAleer, Asymptotic theory for a vector ARMA-GARCH model, to appear in Econometric Theory, 2002c.

Mansfield, E., Patents and innovations; An empirical study, Management Science, 32(2), 173-181, 1986; also in E. Mansfield, Innovation, Technology and the Economy: The Selected Essays of Edwin Mansfield, Vol.II, Edward Elgar, Aldershot, UK, pp. 272-280, 1995.

Marinova, D., Eastern European patenting activities in the USA, Technovation, 21(9), 571-584, 2001.

Nelson, D.B., Stationarity and persistence in the GARCH(1,1) model, Econometric Theory, 6, 318334, 1990.

Nelson, D.B., Conditional heteroscedasticity in asset returns: A new approach. Econometrica, 59, 347370, 1991.

Paci, R., A. Sassu, A., and S. Usai, S. International patenting and national technological specialisation, Technovation, 17(1), 25-38, 1997.

Patel, P., and K. Pavitt, Divergence in technological development among countries and firms, in $\mathbf{J}$. Hagedoorn (ed.), Technical Change and the World Economy: Convergence and Divergence in Technology Strategies, Edward Elgar, Aldershot, pp. 147-181, 1995.

Pavitt, K., Uses and abuses of patent statistics, in A.F.J. van Raan (ed.), Handbook of Quantitative Studies of Science and Technology, Elsevier Publishers, Amsterdam, pp. 509-536, 1988.

Pavitt, K., Transforming centrally planned systems of science and technology: The problem of obsolete competencies, in D.A. Dyker (ed.), The Technology of Transition: Science and Technology Policies for Transition Countries, Central European University Press, Budapest, pp. 43-60, 1997.

Shephard, N., Statistical aspects of ARCH and stochastic volatility, in O.E. Barndorff-Nielsen, D.R. Cox and D.V. Hinkley (eds.), Statistical Models in Econometrics, Finance and other Fields, London: Chapman \& Hall, pp. 1 - 67, 1996.

Soete, L., The impact of technological innovation on international trade patterns: The evidence considered, in C. Freeman (ed.), Output Measurement in Science and Technology, NorthHolland, Amsterdam, pp. 47-76, 1987.

Wong, H. and W. K. Li, On a multivariate conditional heteroscedasticity model, Biometrika, 4, 111-123, 1997. 